\title{
DEPOSITION OF ULTRA-BLACK NICKEL PHOSPHORUS COATINGS
}

\author{
${ }^{1}$ Ekaterina SHCHERBINA, ${ }^{1}$ Aleksey ABRASHOV, ${ }^{1}$ Nelya GRIGORYAN, ${ }^{1}$ Venera ALESHINA, \\ 'Tigran VAGRAMYAN, 'Vladimir MEN'SHIKOV
}

${ }^{1}$ MUCTR - D. Mendeleev University of Chemical Technology of Russia, Moscow, Russia, katerina.sherbin@mail.ru

https://doi.org/10.37904/metal.2020.3552

\begin{abstract}
Absorbing surfaces of solar receivers are coated with black chrome, which provides the surface of steel or aluminum tubes with good absorption properties. However, the chrome coating does not protect well against corrosion because of its high porosity and high internal stresses, which cause a cracking of coatings. In this paper, we investigated two methods for formation of black coatings on chemically formed Ni-P layers: etching in nitric acid and anodic treatment in a phosphoric acid solution. It was found that in the course of processing the black coatings, their roughness and porosity increase. It was shown that nickel oxides $\mathrm{NiO}$ and $\mathrm{Ni}_{2} \mathrm{O}_{3}$ and nickel phosphates are presented in the coating composition. It was established that the heat treatment increases the wear resistance and protective ability of black coatings.
\end{abstract}

Keywords: Chemical nickel plating, ultra-black nickel-containing coatings, steel surface treatment, heat treatment of black coatings, Ni-P coatings, protective properties, roughness, XPS analysis of the composition

\section{INTRODUCTION}

Galvanic black coatings are used to absorb light in optical devices and collectors, which convert light energy into heat, as well as protective and decorative coatings for various products [1-3]. In most cases, black chrome and nickel coatings are used for these purposes [4-10]. Known disadvantages of chromium plating processes are the difficulty of implementation and high energy intensity, due to the need to heat solutions and losses due to the side reaction of hydrogen evolution. To obtain a chrome coating, you need to spend 3 times more electricity than for applying other galvanic coatings. In addition, the chrome coating poorly protects the steel from corrosion as it has high porosity, high internal stresses, leading to cracking of the coating [1].

Known processes of black nickel plating are less energy-intensive and easier to implement, but they have disadvantages such as low levels of protective ability, wear resistance, and poor adhesion to the substrate, especially to steel. As a rule, during the deposition of a black nickel-containing coating, a sublayer of copper or brushed nickel is first applied, on which a black coating is formed, consisting of hydroxides and sulfides of zinc and nickel, which are dispersed in the mass of metallic nickel. The thickness of such coatings does not exceed $0.5-1.0 \mu \mathrm{m}$, and the corrosion resistance is determined mainly by the corrosion resistance of the sublayer [3-5].

A possible alternative to the process of electrodeposition of black chrome and nickel coatings is the process of chemical nickel plating [11-17]. A process feature is the application of uniform in thickness coatings onto complex parts. The resulting coatings are characterized by high corrosion resistance and hardness, which can be significantly increased by subsequent heat treatment.

Therefore, the aim of this work is to study the technical processes of the formation of black coatings on the surface of chemically deposited nickel. 


\section{EXPERIMENTAL MATERIALS}

We used chemical reagents of grades "pur", "p.a." and distilled water to prepare working solutions.

The sheets of cold rolled steel measuring $3 \times 4 \mathrm{~cm}$ were used as samples.

The process of applying black coatings took place in two stages. At the first stage, a Ni-P coating from a solution of the following composition ( $\mathrm{g} / \mathrm{I}$ ) was applied to steel samples: $\mathrm{NiSO}_{4} \cdot 7 \mathrm{H}_{2} \mathrm{O}-35 ; \mathrm{NaH}_{2} \mathrm{PO}_{2}{ }^{*} \mathrm{H}_{2} \mathrm{O}-$ $25 ; \mathrm{CH}_{3} \mathrm{COONa}-18 ; \mathrm{C}_{3} \mathrm{H}_{6} \mathrm{O}_{3}-34 ; \mathrm{C}_{6} \mathrm{H}_{8} \mathrm{O}_{7}-5$. The duration of the process is 3 hours at a temperature of $90-$ $92^{\circ} \mathrm{C}$. At the second stage, the Ni-P coating was blackened due to etching in nitric acid or anodic treatment in phosphoric acid.

The abrasion resistance of nickel-containing coatings was studied using a modernized Taber Elcometer 5135 rotational abrasimeter. Coated flat samples were pressed against a felt disk with the same external load on both arms equal to $3.5 \mathrm{~N} / \mathrm{cm}^{2}$. The abrasion of the samples was carried out during rotation of the felt disk with a rotation speed of $60 \mathrm{rpm}$. The abrasion resistance of the samples was evaluated by the number of cycles until the first signs of abrasion appeared. One cycle amounted to one full circle of felt disk [18].

Corrosion testing of coated samples was carried out in an Ascott S450iP salt spray chamber (UK) in accordance with ASTM B117.

Morphological studies of the surface of coatings and determination of their roughness were carried out using an MPLAPONLEXT 100 objective using a LEXT - OSL 4100 confocal laser microscope.

The composition of the surface layers was studied via X-ray photoelectron spectroscopy (XPS) [19]. Coated samples were fixed in a holder and placed in the pre-evacuation chamber of an OMICRON ESCA+ XPS unit (Germany). The samples were then transferred to the analyzer chamber, where the pressure was maintained at a level no higher than $8 \times 10^{-10}$ mbar. MgKa radiation was used (1253.6 eV; power, $252 \mathrm{~W}$ ). The pass energy of the analyzer was $20 \mathrm{eV}$. To allow for the charge of the samples, the position of the XPS peaks was standardized with respect to the $C$ 1s peak of hydrocarbon impurities from the atmosphere; bonding energy $\mathrm{Eb}$ of the peak was assumed to be $285.0 \mathrm{eV}$. The spectra were decomposed after subtracting the background determined using the Shirley method [20]. The peak position was determined with an accuracy of $\pm 0.1 \mathrm{eV}$. Component ratios were calculated using integrated intensities under the peaks while allowing for photoionization cross sections $\sigma$ of the respective electron shells [21]. Using the integrated intensity of the peaks and the MultiQuant software program [22], the thicknesses of the layers formed on the surface were calculated with allowance for the mean free path of electrons $\lambda$, determined using the formula of Cumpson and Seah [24]. When analyzing the obtained spectra, it was considered that the analyzing beam penetrates the material to the depth of $5 \mathrm{~nm}$, i.e. the resulting spectra correspond to a layer of material of $5 \mathrm{~nm}$ thick.

\section{EXPERIMENTAL WORK}

According to the literary recommendations, the formation of black Ni-containing coatings takes place in two stages: at the first stage, the Ni-P film is deposited, and then in one of two ways it becomes black:

etching in nitric acid $\left(\mathrm{HNO}_{3}\right)$;

anode treatment in phosphoric acid $\left(\mathrm{H}_{3} \mathrm{PO}_{4}\right)$.

\subsection{Determination of the parameters of etching process of Ni-P coatings in nitric acid}

It was found that the maximum black color on Ni-P coatings can be obtained at a nitric acid concentration of 6 $\mathrm{mol} / \mathrm{L}$ or higher, and the processing time is at least 5-5.5 minutes. As expected, the roughness during etching increased from 0.504 to 0.707 microns.

Raising the temperature of the solution above $45^{\circ} \mathrm{C}$ has a bad effect as the color does not become deep enough. It is important to note that at a temperature below $35^{\circ} \mathrm{C}$ a black coating is not formed. 
Photographs of the surface obtained with a confocal microscope indicate that this process is accompanied by the formation of microscopic conical pores perpendicular to the surface. Pore diameter, depth and distance vary from a fraction of a micrometer to several micrometers or from about one to several light wavelengths. Consequently, pores create a black appearance capturing any incident light in a wide spectral range.

The photographs show the Ni-P coating before etching had a thickness of $30 \mu \mathrm{m}$. After etching, the thickness decreased to $7 \mu \mathrm{m}, 2-3$ of which is the formed black layer (Figure 1). Over $20 \mu \mathrm{m}$ of the coating obtained in the first stage were etched.
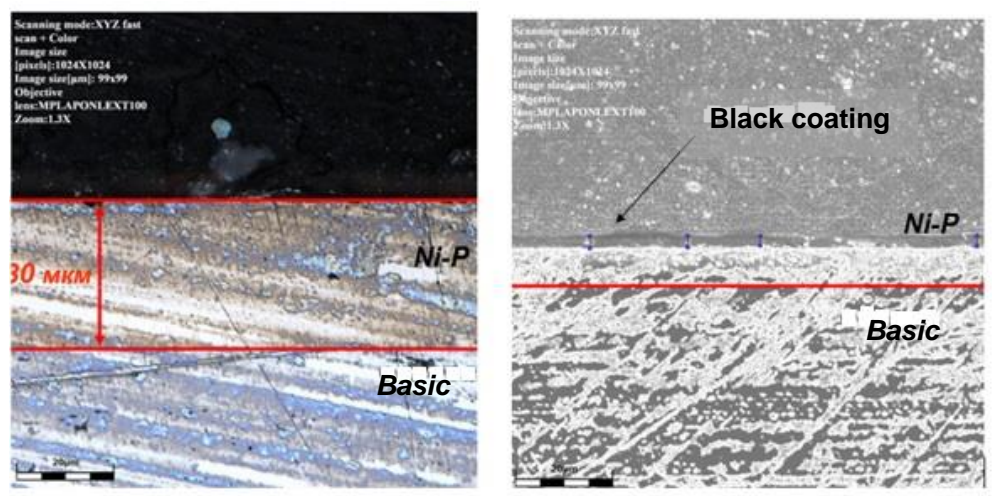

Figure 1 Photographs of cross sections of $\mathrm{Ni}$-containing coatings before and after etching in nitric acid

Using X-ray photoelectron spectroscopy, it was found that oxides of divalent and trivalent nickel, as well as compounds of nickel with phosphorus, are present on the surface (Figure 2).

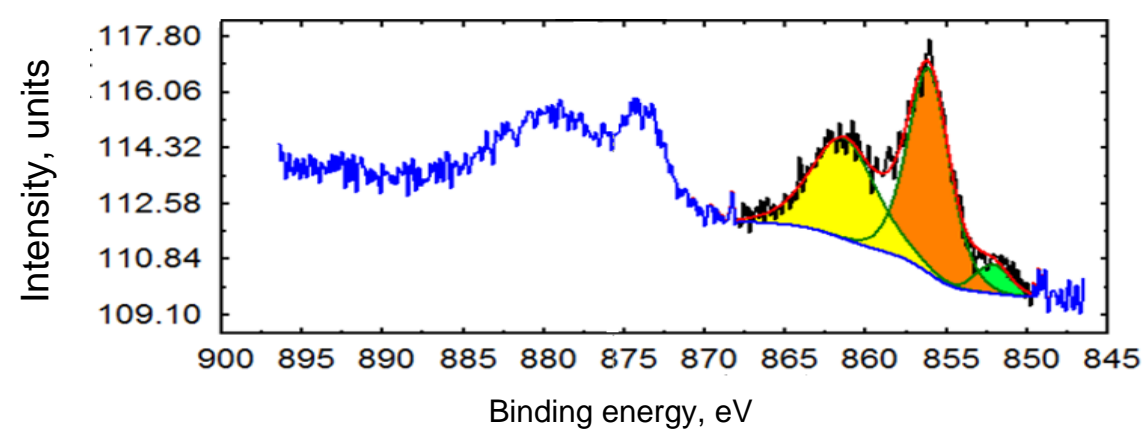

Figure 2 The individual XPS spectrum of $\mathrm{Ni}$

Based on the information received, we assume that the following reactions occur in the process, written using chemical equations (1), (2), (3), (4), (5) and (6).

$$
\begin{aligned}
& \mathrm{Ni}+\mathrm{NO}_{3}^{-} \rightarrow \mathrm{NiO}+\mathrm{NO}_{2}^{-} \\
& 2 \mathrm{Ni}+3 \mathrm{NO}_{3}^{-} \rightarrow \mathrm{Ni}_{2} \mathrm{O}_{3}+3 \mathrm{NO}_{2}- \\
& 3 \mathrm{P}+5 \mathrm{HNO}_{3}+2 \mathrm{H}_{2} \mathrm{O} \rightarrow 3 \mathrm{H}_{3} \mathrm{PO}_{4}+5 \mathrm{NO} \uparrow \\
& \mathrm{Ni}{ }^{2+}+2 \mathrm{H}_{3} \mathrm{PO}_{4} \rightarrow \mathrm{Ni}\left(\mathrm{H}_{2} \mathrm{PO}_{4}\right)_{2}+2 \mathrm{H}^{+} \\
& \mathrm{Ni}^{2+}+\mathrm{H}_{3} \mathrm{PO}_{4} \rightarrow \mathrm{NiHOO}_{4}+2 \mathrm{H}^{+} \\
& 3 \mathrm{Ni}^{+}+\mathrm{H}_{3} \mathrm{PO}_{4} \rightarrow \mathrm{Ni}_{3} \mathrm{PO}_{4}+3 \mathrm{H}^{+}
\end{aligned}
$$

The black coatings were obtained using the treatment in nitric acid, but the significant drawback of this process is the large loss of non-ferrous metal during etching.

- anode treatment in phosphoric acid $\left(\mathrm{H}_{3} \mathrm{PO}_{4}\right)$. 


\subsection{Determination of process parameters for anodizing Ni-P coatings in phosphoric acid}

The dependence of the coating quality on the concentration of phosphoric acid and the voltage on the bath is investigated. It was experimentally found that the blackest coatings are formed at a concentration of $2.7 \mathrm{M}$ and a voltage of 1.1-1.3 $\mathrm{V}$ for a duration of 9 minutes at a room temperature.

Roughness indices were also obtained after anodic treatment in phosphoric acid. The roughness during anodization increases from 0.504 to 0.733 microns.

It was found that after anodizing the Ni-P layer, a greater surface development is observed than in the case of etching in nitric acid. The number of pores is greatly increased.

The coating thickness is etched less from 30 to 12 microns. The thickness of the black layer is only $0.4 \mu \mathrm{m}$ (Figure 3).
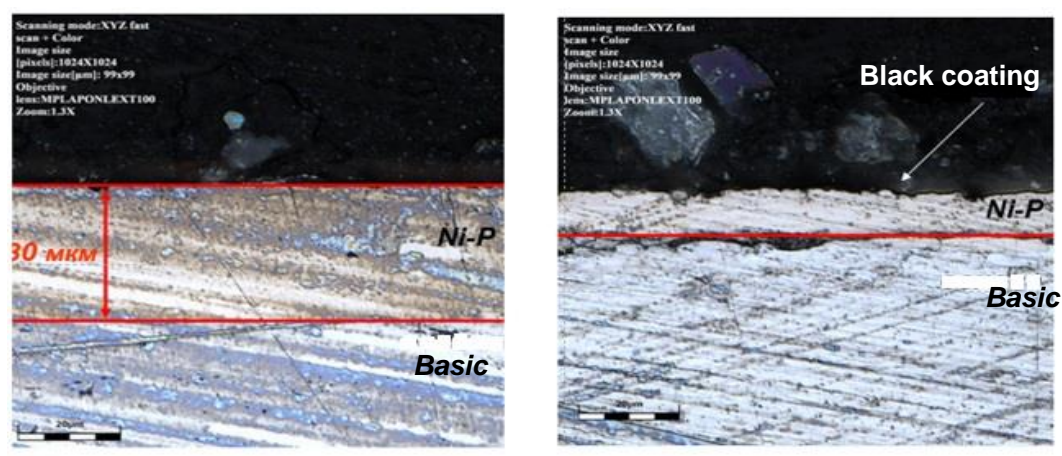

Figure 3 Photos of cross sections of Ni-containing coatings before and after processing in $\mathrm{H}_{3} \mathrm{PO}_{4}$

The individual nickel spectrum showed that the composition of the black film also includes $\mathrm{NiO}, \mathrm{Ni}_{2} \mathrm{O}_{3}$ and nickel phosphates (Figure 4).

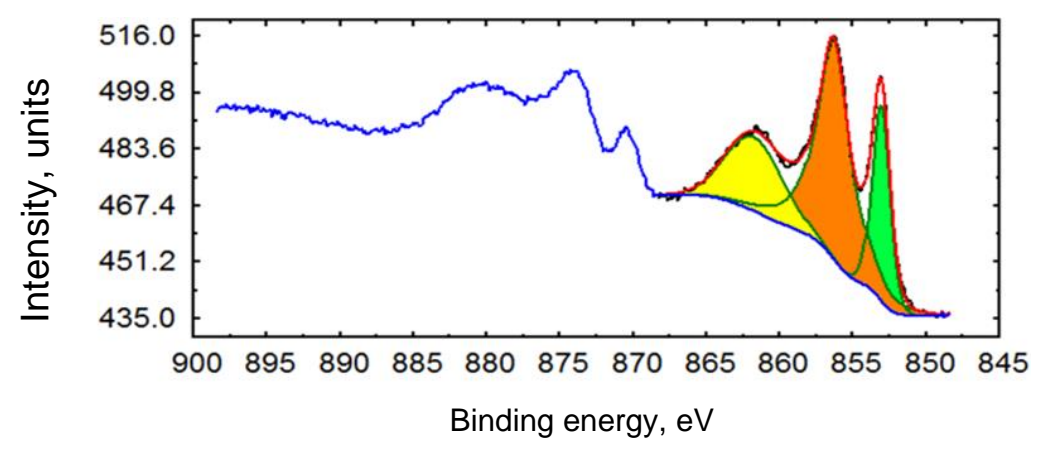

Figure 4 The individual XPS spectrum of $\mathrm{Ni}$

So, we can assume that the following reactions take place, which can be written using chemical equations (7), (8), (9), (10) and (11).

$$
\begin{aligned}
& \mathrm{Ni}+\mathrm{PO}_{4}^{3-} \rightarrow \mathrm{NiO}+\mathrm{PO}_{3}^{3-} \\
& 2 \mathrm{Ni}+3 \mathrm{PO}_{4}^{3-} \rightarrow \mathrm{Ni}_{2} \mathrm{O}_{3}+3 \mathrm{PO}_{3}^{3-} \\
& \mathrm{Ni}^{2+}+2 \mathrm{H}_{3} \mathrm{PO}_{4} \rightarrow \mathrm{Ni}\left(\mathrm{H}_{2} \mathrm{PO}_{4}\right)_{2}+2 \mathrm{H}^{+} \\
& \mathrm{Ni}^{2+}+\mathrm{H}_{3} \mathrm{PO}_{4} \rightarrow \mathrm{NiHPO} 4+2 \mathrm{H}^{+} \\
& 3 \mathrm{Ni}^{2+}+2 \mathrm{H}_{3} \mathrm{PO}_{4} \rightarrow \mathrm{Ni}_{3}\left(\mathrm{PO}_{4}\right)_{2+}+6 \mathrm{H}^{+}
\end{aligned}
$$




\subsection{Tests of the coatings}

It should be noted that black coatings formed by these methods were characterized by smearing. The possibility of eliminating this phenomenon with the help of subsequent heat treatment of coatings is investigated.

It is shown that coatings cease to be smeared during heat treatment in the indicated ranges. For nitric acid, this is $220^{\circ} \mathrm{C}$ for more than half an hour. And for coatings blackened using anodic treatment in phosphoric acid, it is $190^{\circ} \mathrm{C}$ for more than an hour and a half.

In addition, it was revealed that during the heat treatment, the roughness of the coatings increases in both cases. When anodizing in phosphoric acid, the surface development is less than when etching in nitrogen: Ra $=0.865$ and $1.212 \mu \mathrm{m}$, respectively.

The wear resistance of the coatings was investigated. The number of cycles was evaluated until the first signs of abrasion appeared. Table 1 shows that coatings obtained by anodizing in phosphoric acid with subsequent heat treatment have the highest wear resistance.

Corrosion tests have shown that these coatings also have the greatest protective ability.

Table 1 Comparison of the functional characteristics of the resulting coatings

\begin{tabular}{|c|c|c|}
\hline Process & $\begin{array}{c}\text { Wear resistance of black } \\
\text { coatings (number of cycles } \\
\text { until the first signs of loss of } \\
\text { black color appear) }\end{array}$ & $\begin{array}{c}\text { The protective ability of black } \\
\text { coatings (Time until the appearance } \\
\text { of corrosion products of the base, } \\
\text { hour) }\end{array}$ \\
\hline Etching in $\mathrm{HNO}_{3}$ & 850 & 39 \\
\hline Etching in $\mathrm{HNO}_{3}+$ heat treatment & 11750 & 98 \\
\hline Anodization in $\mathrm{H}_{3} \mathrm{PO}_{4}$ & 1050 & 45 \\
\hline Anodization in $\mathrm{H}_{3} \mathrm{PO}_{4}+$ heat treatment & 16000 & 130 \\
\hline $\begin{array}{c}\text { Electrodeposition of black nickel- } \\
\text { containing coating }\end{array}$ & 3000 & 50 \\
\hline Electroplating black chrome coating & 13000 & 120 \\
\hline
\end{tabular}

This table allows you to compare the studied coatings with black electroplated nickel and chrome coatings. It can be seen that the films obtained by anodic treatment in a solution of phosphoric acid followed by heat treatment turn out to be the best in both terms of wear resistance and protective ability.

\section{CONCLUSION}

As a result, methods have been developed for the formation of black layers on chemical coatings in the following ways:

- $6 \mathrm{M} \mathrm{HNO}_{3}, \mathrm{~T}$ (solution) $=40^{\circ} \mathrm{C}$ и т process 5-7 $\mathrm{min}$

- 2,7M H $\mathrm{PO}_{4}, \mathrm{U}=1,1-1,3 \mathrm{~V}, \mathrm{~T}$ (solution) $=20-40^{\circ} \mathrm{C}$

It was revealed that in the process of processing black coatings, an increase in roughness and porosity occurs. It was shown that the composition of the coating includes nickel oxides $\mathrm{NiO}, \mathrm{Ni}_{2} \mathrm{O}_{3}$ and nickel phosphates. It was found that heat treatment increases the wear resistance and protective ability of coatings.

\section{ACKNOWLEDGEMENTS}

"The work was supported by the Mendeleev University of Chemical Technology of Russia. Project 


\section{REFERENCES}

[1] RUDENKO M.F., KRAVTSOV E.E., IDIATULIN S.A. Effective surfaces of solar receivers. Himicheskoe $i$ neftegazovoe mashinostroenie. 1998, no. 7, pp. 33-35.

[2] MESHALKIN V.P., ABRASHOV A.A., VAGRAMYAN T.A., GRIGORYAN N.S., UTOCHKINA D.S. Development of Composition and Investigation of Properties of a New, Environmentally Friendly Molybdenum-Containing Decorative Protec-tive Conversion Coating on Zinc-Plated Surfaces. Doklady Chemistry. 2018, vol. 480, no. 5, pp. $555-558$.

[3] TAKADOUM J. Black coatings: a review. The European physical journal applied physics. 2010, no. 52, pp 30401 (p1-p7).

[4] SOMASUNDARAM S., PILLAI A.M., RAJENDRA A., SHARMA A.K. High emittance black nickel coating on copper substrate for space applications. Journal of Alloys and Compounds. 2015, vol. 643, pp. 263-269.

[5] ESTRELLA-GUTIÉRREZ M.A., LIZAMA-TZEC F.I., ARÉS-MUZIO O., OSKAM G. Influence of a metallic nickel interlayer on the performance of solar absorber coatings based on black nickel electrodeposited onto copper. Electrochimica Acta. 2016, vol. 213, pp. 460-468.

[6] JEEVA P.A., KARTHIKEYAN S., NARAYANAN S. Performance characteristics of corrosion resistant black coatings. Procedia Engineering. 2013, vol. 64, pp. 491-496.

[7] JEEVA P.A., KARTHIKEYAN S., NARAYANAN S. Optimization of black coatings by electro deposition and evaluation of optical properties. International Journal of ChemTech Research. 2013, vol. 5, no. 5, pp. 2405-2409.

[8] NUNES R.A.X., COSTA V.C., SADE W., ARAÚJO F.R., SILVA G.M. Selective surfaces of black chromium for use in solar absorbers. Materials Research. 2018, vol. 21, no. 1, pp. e20170556.

[9] MEDEIROS I.D.M., GOMES K.C. Selective solar surface solar based on black chromium: Influence of electrodeposition parameters in the absorption of surfaces. Materials Research. 2019. vol. 22, no. 2, pp. e20180625.

[10] JEEVA P.A., NARAYANAN S., KARTHIKEYAN S. A review on black coatings for solar energy storaging systems. International Journal of ChemTech Research. 2016, vol. 9, no. 3, pp. 589-596.

[11] TABATABAEI F., RAEISSI K., SAATCHI A., KAZMANLI K., URGEN M. Effect of heat treatment on tribocorrosion of nanostructure Ni-P coatings. Surface Engineering. 2013, vol 29, no 9, pp. 671-676.

[12] PAN Y., HUANG MO J. Content on Wood Colored Electroless Plating Ni Color Influence. Advanced Materials Research. 2013, vol. 650, pp 24-28.

[13] SAXENA V., UMA RANI R., SHARMA A.K. Studies on ultra high solar absorber black electroless nickel coatings on aluminum alloys for space application. Surface \& Coatings Technology. 2006, vol. 201, pp. 855-862.

[14] RANI R.U., SHARMA A.K., MINU C. Studies on black electroless nickel coatings on titanium alloys for spacecraft thermal control applications. Journal of Applied Electrochemistry. 2010, vol. 40, pp. 333.

[15] GUO Z., KEONG K.G., SHA W. Physical and chemical properties of electroless nickel-phosphorus alloys. Journal of alloys and coatings 2003, vol. 358, pp. 112-119.

[16] CHEONG W.J., LUAN B.L., SHOESMITH D.W. Optimization of nanostructured black coatings. Corrosion Science. 2007, vol. 49, pp. 1777-1798.

[17] BROWN R.J.C., BREWER P.J., MILTON M.J.T. The physical and chemical properties of electroless nickelphosphorus alloys and low reflectance nickel-phosphorus black surfaces. Journal of Materials Chemistry. 2002, vol. 10, pp. 2749-2754.

[18] GRIGORYAN N.S., ABRASHOV A.A., VAGRAMYAN T.A., KOSTIUK A.G. Passivation of ferrous and non-ferrous metals in a solution based on gallic acid esters. Chemistry and technology of organic substances. 2017, no 4, pp. 55-63.

[19] Shirley, D.A. High-resolution X-ray photoemission spectrum of the valence bands of gold. Phys. Rev. 1972. B 5, 4709-4713.

[20] Scofield H., J. Hartree-Slater subshell photoionization cross-sections at 1254 and $1487 \mathrm{eV}$. Electron Spectrosc. Relat. Phenom. 1976, vol. 8, pp. 129-137.

[21] MOHAI, M. XPS MultiQuant: multimodel XPS quantification software. Surf. Interface Anal. 2004, vol. 36, pp. 828832. 